\title{
Etiologic Factors Associated with Oral Squamous Cell Carcinoma in Non-Smokers and Non-Alcoholic Drinkers: A Brief Approach
}

\author{
Fabiana VARGAS-FERREIRA ${ }^{1}$ \\ Fernanda NEDEL ${ }^{2}$ \\ Adriana ETGES ${ }^{3}$ \\ Ana Paula Neutzling GOMES ${ }^{3}$ \\ Cristiane FURUSE 3 \\ Sandra Beatriz Chaves TARQUINIO ${ }^{3}$
}

\begin{abstract}
${ }^{1}$ Departament of Social Medicine, UFPel - Federal University of Pelotas, Pelotas, RS, Brazil
${ }^{2}$ Departament of Biotechnology, UFPel - Federal University of Pelotas, Pelotas, RS, Brazil

${ }^{3}$ Department of Oral Pathology, UFPel - Federal University of Pelotas, Pelotas, RS, Brazil
\end{abstract}

\begin{abstract}
Oral squamous cell carcinoma (OSCC) is the fifth most common type of cancer in the world. The effect of some etiological factors is well established in the literature, such as consumption of tobacco and alcohol. However, approximately 15 to $20 \%$ of all oral cancer cases occur in patients without the traditional risk factors, reflecting in numerous cases of OSCC in non-smokers and non-alcoholic drinkers. Also, several studies have suggested a possible association between human papillomavirus and OSCC. Under these aspects, the purpose of this study is to address cases of oral cancer in non-smokers and non-drinkers focusing on the role of HPV, thus contributing to improve the diagnosis and monitoring of OSCC. A computer database search was performed using the Pubmed database. The search key words were: epidemiology, oral squamous cell carcinoma, risk factors and human papillomavirus. It is important to assess patients without the potential risk factors, since this knowledge may help identifying other features associated with the occurrence of oral cancer, enabling an appropriate clinical management and monitoring.
\end{abstract}

Key Words: epidemiology, oral squamous cell carcinoma, human papillomavirus.

\section{INTRODUCTION}

Oral cancer includes cancer of the lip and oral cavity (buccal mucosa, gingiva, hard palate, tongue and floor of mouth) (1) and is considered as the fifth most common type of cancer worldwide (2). In Brazil, estimates for 2010 and 2011 showed nearly 490,000 new cases of cancer (1), and this agrees with the population growth, aging and incidence of chronic diseases.

It has been suggested that the main risk factors associated with oral cancer are smoking and alcohol consumption. The combination of both factors seems to enhance the carcinogenic effect (3), but nearly 15 to $20 \%$ of the cases occur in patients without these traditional risk factors $(3,4)$. The etiology of oral squamous cell carcinoma (OSCC) in individuals without a history of drinking and/ or smoking is unclear. In addition, it has recently been observed a higher proportion of females aged over 70 years old, particularly among alcohol and tobacco non-users (6), with a smaller tumor size and location in non-lingual sites (5). Lately, a viral association has been referred to the development of OSCC for this particular group (tobacco and alcohol non-users), such as papilloma virus (HPV) $(3,4,6)$, especially HPV-16 and HPV-18 (7).

The purpose of this literature review was to discuss on the occurrence of OSCC in patients without history of smoking and/or alcohol drinking, especially concerning the presence of HPV. These patients with disease without the traditional risk factors are an interesting group because the information from their data may be useful to understand the clinical and pathological characteristics associated with OSCC. 


\section{MATERIAL AND METHODS}

Research was carried out on the US National Library of Medicine - (PUBMED) database, as well as the references cited in the papers obtained from the primary search of the aforementioned database. The considered publication period covered 20 years (1991-2011) and the analysis was restricted to papers in Spanish, English or Portuguese. Key words used were: epidemiology; oral squamous cell carcinoma; risk factors and human papillomavirus. Forty-three studies were selected on the basis of the chosen criteria. Moreover, other studies and books were also included in the review.

The review of literature was divided in short topics: a) Epidemiology of oral squamous cell carcinoma and clinical aspects related to alcohol and tobacco non-users; b) The role of alcohol and smoking habits in oral carcinogenesis; and c) The role of HPV in oral carcinogenesis.

\section{REVIEW OF LITERATURE}

\section{Epidemiology of Oral Squamous Cell Carcinoma and Clinical Aspects Related to Alcohol and Tobacco Non-Users}

OSCC is a heterogeneous but largely preventable disease with molecular abnormalities (1). Its epidemiology is complex because this condition shows multiple etiologic factors and the data are not available (in quantity and quality) for all the countries.

According to the primary localization, OSCC affects nearly 15,000 men and women in Rio Grande do Sul (each year), a state localized in Southern Brazil and the incidence is approximately 16.39 new cases per 100,000 inhabitants (1). It is important to point that among all types of oral cancers, OSCC accounts for almost all notifications (8), and Brazil has the highest incidence rates of this condition among male individuals (1) compared with the other South American countries.

OSCC remains a significant cause of morbidity and mortality. For 2020, the estimates are that nearly $60 \%$ of new cases of OSCC will be diagnosed in developing countries like Brazil (1) and it is important to consider that at least $1 / 3$ of the new cases are preventable (1).

In general, older individuals (over 50 years old), mainly men (smokers and alcohol drinkers) are affected $(9,10)$. However, studies have shown that there has been an increase of incidence among the younger population
$(11,12)$, ranging from 0.4 to $3.6 \%(12)$. Indeed, there are cases of women over 70 years old (6) and patients without history of smoking and/or alcohol consumption (13).

The literature has shown a higher proportion of cases among older men $(9,10)$; however, there is no significant difference between males and females in relation to the prognosis (2). Survival rate is lower among females because they tend not to accept treatment (2). After metastasis, the survival rate (five years) is lower than $50 \%$ in most cases (2), which indicates high morbidity and mortality associated with this disease. This low rate may be associated with late diagnosis and use of inappropriate therapy (2).

The main risk factors are smoking $(10,11)$ and alcohol consumption (8-10). Petti (10) revised investigations about prevalence and/or incidence of OSCC and concluded that $1 / 4$ of cases are attributable to smoking, between 7 to $19 \%$ to alcohol consumption and 10 to $15 \%$ to micronutrient deficiency. A case-control study conducted in India, with patients diagnosed with oral cancer $(n=388)$ and an equal number of age and sexmatched controls to assess the effect of lifestyle factors (tobacco chewing, smoking, alcohol drinking, diet and dental care) on the risk of oral cancer. The results showed that use of tobacco (chewing) alone and alcohol drinking emerged as significant risk factors for oral cancer (odds ratio - $\mathrm{OR}=11.34$ ). They emphasize that these risk factors are modifiable and it is important to increase awareness among the general public and policy makers as a first step in the prevention and control of OSCC (2).

Case-control studies showed an association between socioeconomic status and the outcome $(9,14,15)$. It is relevant to study the impact of socioeconomic status on oral cancer (mainly, in epidemiologic data) because this oral condition involves risk factors and use/quality of care services (15). In general, people with low socioeconomic status and lower schooling level show higher frequency of the outcome, higher incidence and mortality, and lower quality of life and survival rates (9,14-15). The higher prevalence of smoking and alcohol consumption is usually found in the underprivileged strata (16), where people have less access to the treatment and social support is reduced (15).

In another case-control study carried out in Sweden, 396 cancer-free controls were identified and matched by age, gender and county. Out of these individuals, $320(81 \%)$ agreed to take part in the study. Their results showed that the individuals reported a higher consumption of alcohol than the controls. More 
than $350 \mathrm{~g}$ of alcohol per week $(\mathrm{OR}=2.6 ; 95 \% \mathrm{CI} 1.3-5.4)$ and $11-20$ cigarettes per day $(\mathrm{OR}=2.4 ; 95 \% \mathrm{CI} 1.3-4.1)$ were dose-dependent risk factors. There was a significant relationship between high-risk HPV infection and OSCC $(\mathrm{OR}=63 ; 95 \% \mathrm{CI} 14-280)$. The high-risk HPV types found in the oral cavity were the same types observed in cervical cancer. They concluded that among other studied possible risk factors, high-risk HPV infection appears to be the strongest (8).

The main locations of OSCC are the tongue and floor of mouth, with $50 \%$ and $35 \%$ of the cases, respectively (1). The possible explanation may be related to the harmful habits, such as smoking and alcohol consumption (1) and higher susceptibility to the action of risk factors (2). Data from the Department of Oral Pathology, UFPel, Brazil, revealed a different location when the patient is a non-smoker and/or alcohol consumer (Fig. 1) for example, in the maxillary alveolar ridge However, some cases of OSCC are localized in tongue and in females (older) (Fig. 2).

\section{The Role of Alcohol and Smoking Habits on Oral Carcinogenesis}

The development of oral carcinogenesis shows multifactorial etiology - endogenous (genetic) and exogenous (environmental and behavioral) factors. The main risk factors associated with OSCC: smoking (9-11), alcohol consumption (8-10), demographic and socioeconomic variables $(10,14,15)$, lack of or irregular

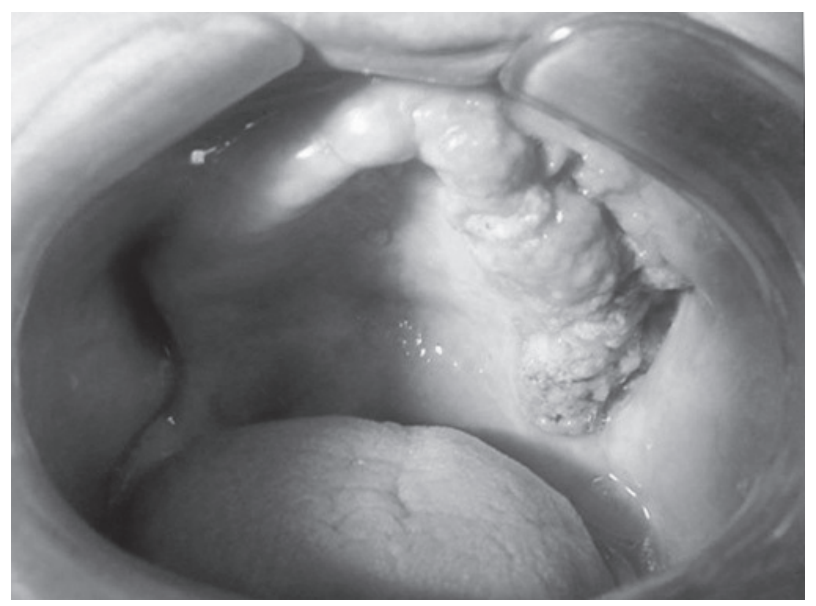

Figure 1. Intraoral clinical image of an 83-year old woman, nonalcohol drinker and non-smoker with a lesion in the maxillary alveolar ridge on the left side, involving the area of molar up to the midline. OSCC (grade III). oral hygiene (8-9), occupational exposures (15) and defective dental prostheses (8).

Smoking is considered a relevant public health problem and is related to more than 50 different pathological alterations (1). The harmful influence of smoking on oral tissues is due to the fact that it contains some 300 carcinogenic compounds that are converted into reactive metabolites capable of interacting with DNA by the action of oxidative enzymes (2). Out of these, 60 have known carcinogenic action, especially polycyclic aromatic hydrocarbons and tobacco-specific nitrosamines found in the tar. Other carcinogenic substances, such as nickel and cadmium, radioactive elements like carbon-14 and polonium-210, and even residues of pesticides used in tobacco growing can also be detected in tobacco and tobacco smoke. In addition to the action of carcinogenic substances, continuous exposure to the heat resulting from the tobacco combustion further aggravates the aggression to the oral mucosa $(2,8)$.

The literature suggests that individuals without history of smoking and/or alcohol consumption may have harmful factors, but smoking increases the risk of development of oral cancer (nearly 10 times) than their counterparts (2).

Alcohol consumption is associated with oral cancer, with independent action and synergistically with tobacco (15). There is a hypothesis that buccal epithelium is more permeable to the action of other carcinogens, such as tobacco products, due to the previous action of ethanol on their cells $(2,7,8)$.

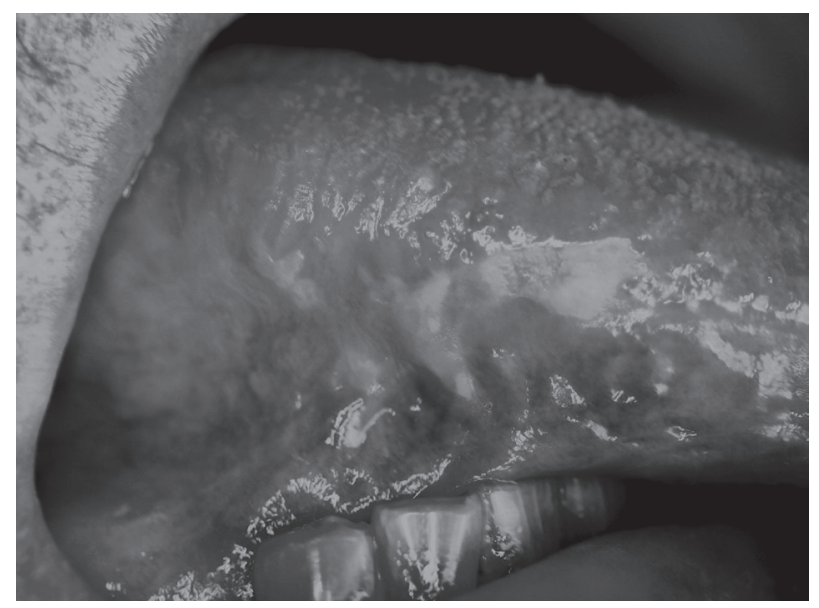

Figure 2. Intraoral clinical image of an 84-year old woman without history of smoking and alcohol consumption showing an opaque plaque in tongue (right side), with smooth and rough surface. Carcinoma in situ. 


\section{The Role of HPV in OSCC Etiology}

For almost a half century the role of HPV in the etiology of cervix cancer has been demonstrated and its carcinogenic action has been well established (16). In the 1980's, the possible correlation between HPV and its role in the etiology of oral cancer was first evaluated. The cytopathic changes of HPV in oral malignant and premalignant lesions were described as identical to those previously found in precancerous lesions and carcinomas of the uterine cervix (17). Subsequently, a series of studies with different outlines evaluated the role of HPV virus in carcinomas and other premalignant lesions $(3,4,6)$, however, the results are still inconclusive.

HPV are a group of host-specific DNA virus with a remarkable epithelial cell specificity (keratinocytes). The involvement of HPV in the carcinogenesis of OSCC was based in the following elements: 1) specificity of HPV virus to epithelial cells; 2) the extensive knowledge of the oncogenic potential of high-risk HPV (HR HPV) genotype in the pathogenesis of anogenital neoplastic disease, especially cervical squamous cell carcinoma; 3 ) the morphological resemblance between oropharyngeal and genital epithelium. The ability to insert specific DNA fragments into the host cellular genome has provided the HR HPV an oncogenic potential. As a result of this integration some essential functions of tumor suppressor factors are eliminated, resulting in defects in apoptosis, DNA repair mechanisms, cell cycle regulation and cell immortalization $(18,19)$.

For OSCC lesions, the prevalence of HPV virus varies in the literature (20-50\%). Such variability can be attributed to several factors such as geographic and ethnic differences; sample types (biopsy, smear); different preparation methods (fixed or frozen specimens); HPV detection methods with different levels of sensitivity (southern blotting, hybridization in situ polymerase chain reaction) and especially the erroneous classification of tongue lesion in respect to their oropharyngeal location $(4,18,19)$.

The simple identification of HPV DNA is insufficient to prove its oncogenic capacity in OSCC lesions (6). Conversely, the failure to observe this virus does not exclude its possible role in the initiation of oral carcinogenesis, it is argued that the transformed cell could lose the viral DNA (6). However, this hypothesis is highly questionable since the persistence of HPV oncoproteins E6 and E7 seems to be required for the perpetuation of malignancy in cervix carcinoma (20).

Some authors have suggested that the carcinogenic potential of HPV can be the association with some of the considered risk factors (tobacco smoking and alcohol consumption) and genetic factors (21). In fact, a significant correlation between HPV integration and reduced or absent exposure to known risk factors for OSCC has been demonstrated. In agreement, other authors $(22,23)$ showed a higher percentage of smokers and drinkers in HPV-negative head and neck carcinomas. Therefore, it is believed that nonsmoking individuals have a greater probability of developing tumors related to HPV than individuals who smoke. This could be explained by evidence that while alcohol acts as an enhancer of oral mucosa permeability altering its structure and aiding penetration of HPV through the epithelial layers, tobacco promotes epithelium keratosis inhibiting viral infiltration and maturation (18). In contrast, other studies have found no differences in smoking between HPV-positive and HPV-negative patients $(23,24)$.

Another important issue to be addressed is the prevalence of HPV infection from oral-genital sexual contact in young adults. Studies have shown that HPV that infects genital area can also infect the oral cavity, although some studies have suggested that the frequency of oral infection is less than the anogenital (25). However this contrasts with the prevalence of cases of OSCC in non-smoking and non-drinking aged women, which raises doubts about the etiology of HPV in this specific population (4).

\section{CONCLUDING REMARKS}

Oral cancer is a relevant public health problem. The increased incidence is related to aging and to development of chronic diseases. The literature has highlighted the important role of tobacco and alcohol consumption in oral carcinogenesis, but nearly $20 \%$ of OSCC cases have shown unknown etiology. There has been an increased number of cases among individuals without history of smoking and/or alcohol consumption and in female (younger and older). Another interesting aspect refers to the potential role of HPV associated with OSCC.

It is important to investigate other possible factors associated with the occurrence of OSCC, enabling appropriate clinical management and monitoring. Moreover, improving the incidence, mortality, and 
survival rates of oral cancer requires a multi-tier structural approach that targets society, dentists, communities, and the individual (25).

\section{RESUMO}

O carcinoma espinocelular (CEC) de boca é o quinto mais comum no mundo. $\mathrm{O}$ efeito de alguns fatores etiológicos está bem estabelecido na literatura, como o fumo e o consumo de álcool. No entanto, aproximadamente 15 a $20 \%$ dos casos de câncer bucal acometem pacientes sem os tradicionais fatores de risco e isso se traduz em inúmeros casos de CEC bucais em indivíduos não fumantes e não etilistas. Além disso, dados da literatura têm sugerido uma possível associação entre o vírus papiloma humano (HPV) e o carcinoma espinocelular de boca. Em virtude desse aspecto, desenvolveu-se este trabalho na perspectiva de revisar as características mais associadas a esse grupo de pacientes, contribuindo assim para a melhoria no diagnóstico e no acompanhamento dos mesmos. Os artigos que serviram de apoio para o estudo foram localizados por meio da base de dados Pubmed, utilizando os descritores "epidemiologia", "carcinoma espinocelular de boca", "fatores de risco" e "vírus papiloma humano". É importante avaliar pacientes sem tais fatores de risco, uma vez que o conhecimento pode auxiliar na análise de outras características associadas com a ocorrência de carcinoma. Além disso, possibilita melhorar o manejo clínico e monitoramento.

\section{REFERENCES}

1. National Institute of Cancer - INCA. Estimative 2010 - Incidence of Cancer in Brazil. Rio de Janeiro: Ministry of Health 2009;100p.

2. Subapriya R, Thangavelu A, Mathavan B, Ramachandran CR, Nagini S. Assessment of risk factors for oral squamous cell carcinoma in Chidambaram, Southern India: a case-control study. Eur J Cancer Prev 2007;16:251-256.

3. Mannarini L, Kratochvil V, Calabrese L, Gomes Silva L, Morbini P, Betka J et al.. Human Papilloma vírus (HPV) in head and neck region: review of literature. Acta Otorhinol Ital 2009;29:119-126.

4. Siebers TJH, Merkx MAW, Slootweg PJ, Melchers WJG, Cleef PV, Wilde PCM. No high-risk HPV detected in SCC of the oral tongue in the absolute absence of tobacco and alcohol - a case study of seven patients. Oral Maxillofac Surg 2008;12:185-188.

5. Dahlstrom KR, Little JA, Zafereo ME, Lung M, Wei Q, Sturgis EM. Squamous cell carcinoma of the head and neck in never smoker-never drinkers: a descriptive epidemiologic study. Head Neck 2008;30:75-84.

6. Feller L, Wood NH, Khamissa RAG, Lemmer J. Human papillomavirus-mediated carcinogenesis and HPV-associated oral and oropharyngeal squamous cell carcinoma. Part 2: Human papillomavirus associated oral and oropharyngeal squamous cell carcinoma. Head Face Med 2010;6:15.

7. Scully C, Porter S. ABC of oral health. Oral cancer. BMJ 2000;321:97-100.

8. Rosenquist K. Risk factors in oral and oropharyngeal squamous cell carcinoma: a population-based case-control study in Southern Sweden. Swed Dent J Suppl 2005;179:1-6.

9. Balaram P, Sridhar H, Rajkumar T, Vaccarella S, Herrero R, Nandakumar A, et al.. Oral cancer in southern India: the influence of smoking, drinking, paan-chewing and oral hygiene. Int J Cancer
2002;98:440-445.

10. Petti S. Lifestyle risk factors for oral cancer. Oral Oncol 2009;45:340-350.

11. Llewellyn CD, Linklater K, Bell J, Johnson NW, Warnakulasuriya S. An analysis of risk factors for oral cancer in young people: a case-control study. Oral Oncol 2004;40:304-313.

12. Andisheh-Tadbir A, Mehrabani D, Heydari ST. Sociodemographic and etiological differences of head and neck squamous cell carcinoma in young and old patients in Southern Iran. J Craniofac Surg 2010;21:126-128.

13. Toner M. O'Reagan EM. Head and neck squamous cell carcinoma in the young: a spectrum or a distinct group? Part 1. Head Neck Pathol 2009;3:246-248.

14. Madani AH, Dikshit M, Bhaduri D, Jahromi AS. Relationship between selected socio-demographic factors and cancer of oral cavity - a case-control study. Cancer Inform 2010;9:163-168.

15. Boing F, Antunes JLF. Socioeconomic conditions and head and neck cancer: a systematic literature review. Cien Saude Colet 2011:16:615-621.

16. Steben M, Duarte-Franco E. Human papilomavirus infection: epidemiology and pathophysiology. Gynecol Oncol 2007;107:5255.

17. Syrjänen KJ, Mäntyjärvi R, Väyrynen M, Yliskoski M, Syrjänen SM, Saarikoski S, et al.. Cervical smears in assessment of the natural history of human papillomavirus infections in prospectively followed women. Acta Cytol 1987;31:855-865.

18. Campisi G, Panzarella V, Giuliani M, Lajolo C, Di Fede O, Falaschini S, et al.. Human papillomavirus: its identity and controversial role in oral oncogenesis, premalignant and malignant lesions (review). Int J Oncol 2007;30:813-823.

19. Termine N, Panzarella V, Falaschini S, Russo A, Matranga D, Lo Muzio L, et al.. HPV in oral squamous cell carcinoma vs head and neck squamous cell carcinoma biopsies: a meta-analysis (19882007). Ann Oncol 2008;9:1681-1690.

20. Gillison ML. Human papillomavirus and prognosis of oropharyngeal squamous cell carcinoma: implications for clinical research in head and neck cancer. J Clin Oncol 2006;24:56235625 .

21. Albuquerque R, López-López J, Marí-Roíg A, Jané-Salas E, Rosseló-LLabrés X, Santos JR. Oral tongue squamous cell carcinoma (OTSCC): alcohol and tobacco consumption versus non-consumption. A study in a Portuguese population. BDJ 2011;22:517-521.

22. Hafkamp HC, Speel EJ, Haesevoets A, Bot FJ, Dinjens WN, Ramaekers FC, et al.. A subset of head and neck squamous cell carcinomas exhibits integration of HPV 16/18 DNA and over expression of p16INK4A and p53 in the absence of mutations in p53 exons 5-8. Int J Cancer 2003;107:394-400.

23. Anaya-Saavedra G, Ramírez-Amador V, Irigoyen-Camacho ME, García-Cuellar CM, Guido-Jiménez M, Méndez-Martínez R, et al.. High association of human papillomavirus infection with oral cancer: a case-control study. Arch Med Res 2008;39:189-197.

24. Paz IB, Cook N, Odom-Maryon T, Xie Y, Wilczynski SP. Human papillomavirus (HPV) in head and neck cancer. An association of HPV 16 with squamous cell carcinoma of Waldeyer's tonsillar ring. Cancer 1997;79:595-604.

25. Saman DM. A review of the epidemiology of oral and pharyngeal carcinoma:update. Head Neck Oncol 2012;4:1.

Received May 21, 2012 Accepted September 21, 2012 